\title{
Assessing R\&D quality in rehabilitation technology development. The case of Roessingh Research and Development
}

\author{
Petra C. de Weerd-Nederhof ${ }^{1}$, Willem H. van Harten ${ }^{2}$, \\ Harry Boer ${ }^{1}$ and Hermie Hermens ${ }^{2}$
}

\footnotetext{
${ }^{1}$ University of Twente, Faculty of Technology and Management, Department of Technology and Organisation, P.O. Box 217, 7500 AE Enschede, The Netherlands

${ }^{2}$ Roessingh Research and Development B.V., P.O. Box 310, 7500 AH Enschede, The Netherlands
}

This paper presents a framework for describing and evaluating the links between the design of the $R \& D$ function, its context and its performance. As a first step towards the development of a quality assurance system, this framework was used to assess $R \& D$ quality performance at a privatized $R \& D$ unit connected to a rehabilitation centre (Roessingh Research and Development). The results suggest that the framework is a useful instrument for managers to identify and understand the strengths and weaknesses of the $R \& D$ function, both with respect to its present, operational (quality) performance as well as its strategic flexibility, i.e. its readiness to adapt to, anticipate, or even create future (quality) performance requirements. The paper concludes with managerial implications with regard to the choice of an appropriate quality assurance system for Roessingh R\&D, thus illustrating briefly how the framework can be used to apply ISO/BS quality standards (which are aimed at product development) in more fundamental R\&D.

\section{Introduction}

\section{$R \& D$ and $T Q M$}

Research \& Development (R\&D), in its broadest sense, is the process of transforming customer demands and technological advancements (inputs) into new product designs (outputs). Total Quality Management (TQM) means that it is the responsibility of all people in the organization that all products delivered by the company meet the needs and expectations of customers and that all management activities are aimed at/ geared toward systematic and continuous improvement of all organizational processes. The quality of a product is to a high extent determined by its design (Figure 1); consequently, quality management in upstream processes such as market research and in particular R\&D needs considerable attention (Bossink et al., 1992). Even more, according to some authors, quality management (i.e. TQM) applied to $R \& D$, is the key to optimization of the R\&D process (Hedge, 1989; Murray, 1987). In this paper the development of quality assurance of a privatized Research and Development unit for rehabilitation technology will be described. Due to the raised level of activities and connected publicity, cooperation with companies and industry on items such as contract research and product development is growing. A study was undertaken to develop a systematic approach for quality assurance, following the need both to guarantee a forefront position of the research programmes and development activities in the future as well as to ensure a smooth development of activities in closer cooperation with industry. This study was performed in collaboration with researchers from the faculty of Tech- 
Petra C. de Weerd-Nederhof et al.

expected specifications by the customer

$$
\text { specification } \quad \sim \text { Marketing }
$$

perceived specifications by the company

$$
\begin{array}{|ll}
\text { product design } & \sim \mathbf{R} \& \mathbf{D} \\
\text { Process design } & \sim \text { Process Planning/Engineering }
\end{array}
$$

intended specifications by the company

manufacturing
assembly

realised specifications by the company

$$
\text { information } \quad \sim \text { Marketing, Sales and Service }
$$

perceived specifications by the customer

Figure 1. Quality is satisfying customer needs and expectations.

nology and Management of the University of Twente.

\section{Research objective}

The objective of the research carried out by the researchers of the University of Twente, was to obtain more insight into the influence of organizational design and contextual characteristics on R\&D quality performance. In order to be able to evaluate R\&D quality performance and to identify possible areas for improvement, a six step approach, based on a generic operations strategy framework, and three tools for mapping (the links between) the R\&D function, its context and performance, were developed.

\section{Organisation of the paper}

This paper is organized as follows. First, the theoretical framework underlying the research is described. Then, the six steps and the three tools and their application in the case of Roessingh R\&D are illustrated and discussed. The paper concludes with managerial implications for Roessingh R\&D and explains the choice for a dynamic, concep- tual quality assurance system, mainly based on BS 7000 standards.

\section{Operations strategy framework}

\section{Operations strategy and organization theories}

The point of departure in the present research has been the hypothesis that an internally and externally consistent organizational system is effective, whether the system is a network of organizations, an organization or an organizational subsystem (e.g. a group, department or function). Applied to the design of the R\&D function, the consistency requirement means that it must be ensured that the design decisions regarding the $R \& D$ function and its links with the intra- and extra-organizational (task) environment are consistent, i.e. align properly, and contribute to the R\&D strategy, the other functional strategies, and corporate strategy, from which the functional strategies ought to be derived (based on Skinner, 1985; Hayes and Wheelright, 1984).

The framework depicted in Figure 2 illustrates the above. This framework is based on 


\section{\begin{tabular}{|r|r}
\hline business & operations \\
\hline
\end{tabular}}

\begin{tabular}{|c|c|c|c|c|c|c|c|}
\hline $\begin{array}{c}\text { corporate goals } \\
\text { and strategy }\end{array}$ & $\begin{array}{l}\text { market } \\
\text { strategy }\end{array}$ & $\begin{array}{c}\text { qualifying and } \\
\text { order winning } \\
\text { criteria }\end{array}$ & $\begin{array}{l}\text { company } \\
\text { performance } \\
\text { criteria }\end{array}$ & $\begin{array}{c}\text { R\&D } \\
\text { performance } \\
\text { criteria }\end{array}$ & $\begin{array}{c}\text { R\&D } \\
\text { process } \\
\text { design }\end{array}$ & $\begin{array}{c}\text { R\&D } \\
\text { technology } \\
\text { design }\end{array}$ & $\begin{array}{c}\text { R\&D } \\
\text { organisation } \\
\text { design }\end{array}$ \\
\hline
\end{tabular}

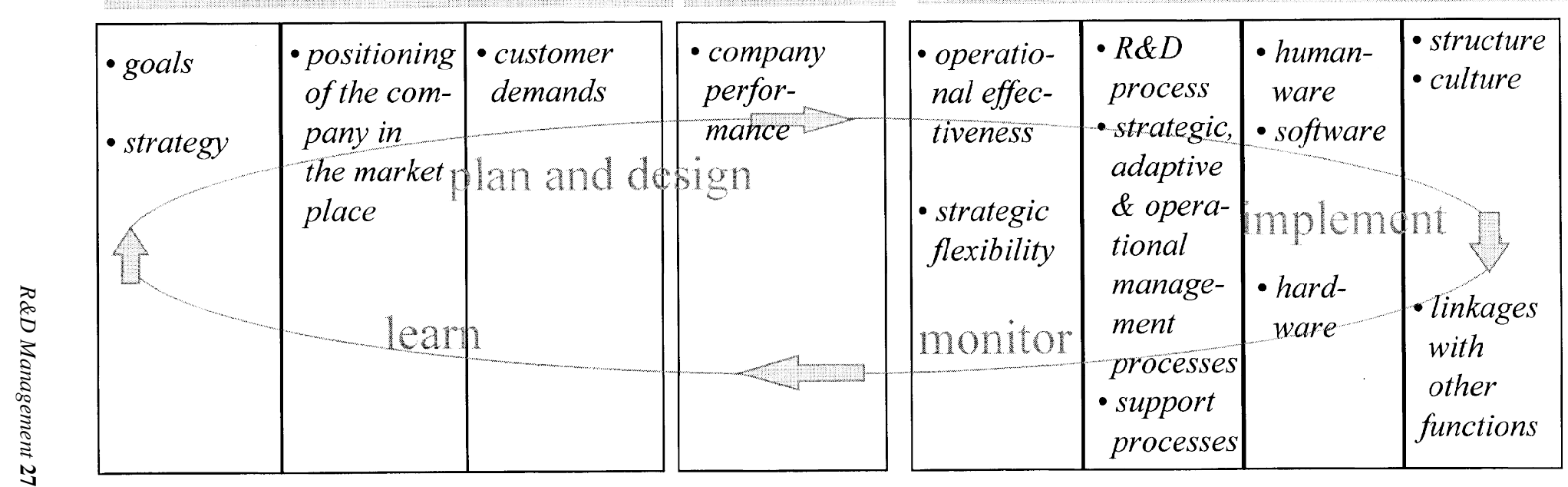

Figure 2. The Operations Strategy Framework applied to the R\&D function. 


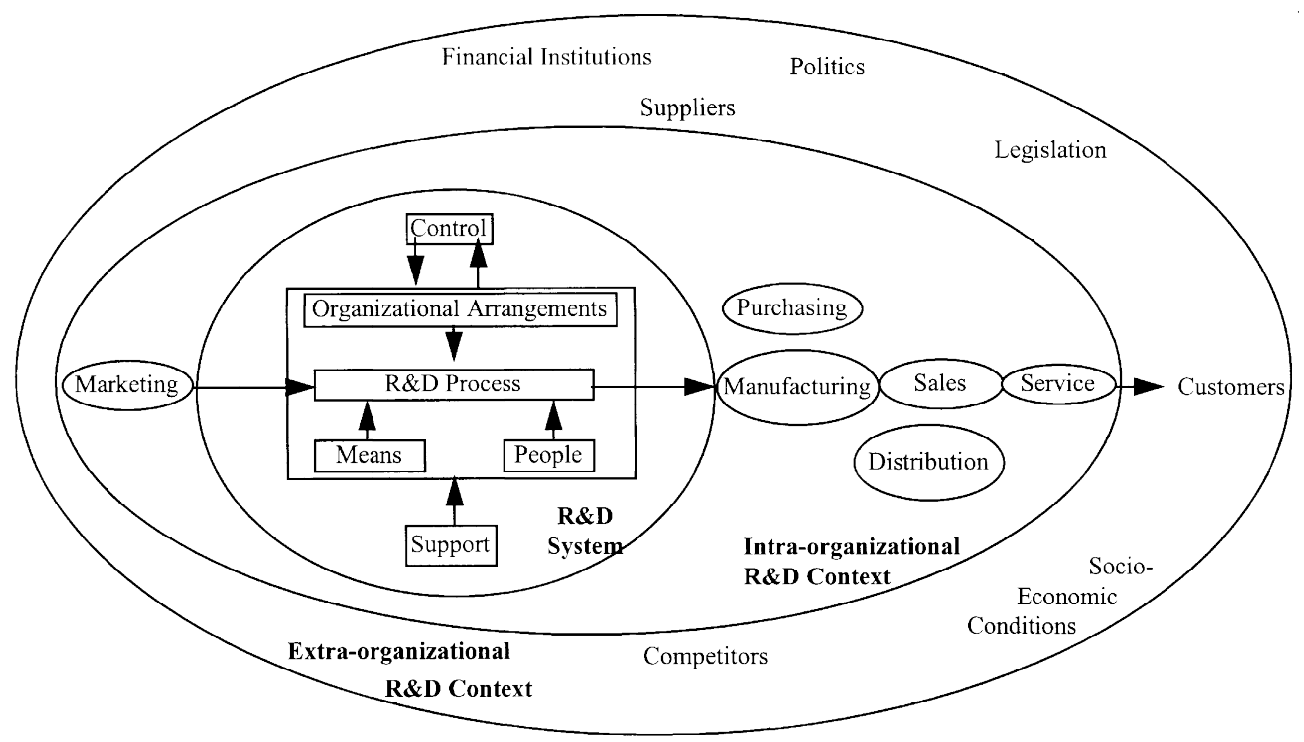

Figure 3. The R\&D function and its intra- and extra-organizational context.

a similar model proposed by Hill (1995), which we adapted for our previous work on the design of organizations (e.g. Boer and Krabbendam, 1991; Draaijer and Boer, 1995; Paashuis and Boer, 1995) and contingency theories of organizations, and then applied to the R\&D function. The framework emphasizes that:

(1) R\&D strategy is about making and implementing decisions about the design of the R\&D function, within the overall organization design of the company; i.e. including the linkages with other functions. This means setting performance criteria which are derived from company performance criteria, and designing the operational, management and support processes, the technologies (incorporated in people and resources) needed to perform these processes and the organizational arrangements needed to divide and co-ordinate the processes/the ensuing liaisons (last 5 columns in Figure 2).

(2) these decisions ought to align properly and must be examined in the light of their contribution, in terms of capacity and capability, towards the R\&D strategy, the other functional strategies, and corporate strategy (first 3 columns in
Figure 2), in order to ensure that the $R \& D$ function contributes effectively to the company's desired performance in the market place (both now and in the future).

All this:

(3) ought to be an ongoing process of planning and designing - implementing monitoring - learning - (re-)planning and (re-)designing - ... etc., which illustrates that designing the R\&D function is a dynamic rather than a static activity.

Note that similar frameworks can be drawn up for other organizational functions such as manufacturing, sales and service. In the remainder of this paper we shall not discuss the whole framework. We concentrate on the last 4 columns of the framework:

(1) the design of the $R \& D$ process(es), technology(/ies) and organization (including the most important linkages with other relevant functions);

(2) the contingency relationships between the elements of the R\&D function, and between the R\&D function and its intra- 
organizational and extra-organizational context (see Figure 3);

(3) the performance of the R\&D function.

\section{Assessing quality performance}

Performance measurement is a notoriously difficult problem, which starts with defining organizational effectiveness. Traditional approaches to organizational effectiveness recognise that organizations:

1. bring material and informational inputs as well as technologies (resources, people) in from the environment: this has been called system resource or input effectiveness;

2. use these technologies to transform inputs into outputs (products, services): known as internal process or transformation effectiveness;

3. then deliver these outputs back to the environment: goal or output effectiveness.

The more recent stakeholder approach accepts these classes of organizational effectiveness but recognizes in addition that organizations do many different things, have many outcomes and many stakeholders so that several different, possibly conflicting indicators are needed to measure effectiveness. The competing values approach emphasizes that, at the end of the day, it is management that must choose the goals they wish to pursue and decide which goals will be given less priority. In the present research we essentially adopted this approach. That is: we developed and applied a set of metrics for
R\&D quality, but neither imposed any choice between metrics upon the managers involved nor expressed our opinion in terms of 'you're doing well' or, 'your company is performing poorly', but left it to the managers to arrive at such or other conclusions. The only thing we pretended, and proved successfully to be able to do, was to help them, given the measurements made, to identify strengths, weaknesses and possibilities for improvement.

It should be noted that great care has to be taken when determining and using indicators for performance measurement in $R \& D$. Perhaps '.. the most objective and comprehensive measure of $R \& D$ performance is a measure of the success (in terms of profits, market share etc.) the company eventually achieves in the marketplace due to the R\&D activities. However, when trying to calculate this measure, major problems are encountered. The first problem is the time lag (...). The second problem is the difficulty in isolating the contribution of $R \& D$ to company success ...' (Kerssens-van Drongelen, 1995).

Keeping these problems in mind explicitly, we propose to assess $R \& D$ performance on two levels. Firstly, when looking at the actual $\mathrm{R} \& \mathrm{D}$ projects, performance is assessed in terms of Operational Effectiveness. In line with Brown and Eisenhardt (1995) we decided to assess this level of R\&D performance both in terms of Product Concept Effectiveness (fit with market demands and fit with firm competencies) and Process Performance (speed, productivity, costs, flexibility in terms of operational feedforward control/corrective actions).

Table 1. Steps for quality assessment in R\&D using the Operations Strategy Framework.

\begin{tabular}{ll}
\hline Steps & Activities \\
\hline 1. & $\begin{array}{l}\text { a. Collect basic information on the company. } \\
\text { b. Complete columns } 1-4 \text { of the Operations Strategy Framework. }\end{array}$ \\
2. & $\begin{array}{l}\text { a. Derive a specific Quality Performance Profile for R\&D (column 5). } \\
\text { b. Derive an R\&D Function Profile by completing columns 6-8. }\end{array}$ \\
3. & Describe R\&D elements and their attributes contributing to quality. \\
4. & Describe R\&D context characteristics influencing quality. \\
5. & Assess Quality by completing the R\&D Function Profile using the results of steps 3 and 4. \\
6. & $\begin{array}{l}\text { Identify areas for improvement by relating the R\&D Function Profile with the specific Quality Performance } \\
\text { characteristics for R\&D as defined in step 2a and/or Quality Performance indicators from quality standards } \\
\text { and benchmarks. }\end{array}$ \\
\hline
\end{tabular}


Petra C. de Weerd-Nederhof et al.

Although we focus on the R\&D function and consider things like company strategy as a given in our research, we think it is very important to also assess the readiness of the R\&D system to adapt to, anticipate or even create future performance requirements by (continuously) evaluating and learning within, between, and among projects in order to improve the capacity to manage R\&D processes, (technical) competencies and the innovative ability of the $\mathrm{R} \& \mathrm{D}$ system. In order to assess this level of $R \& D$ performance, which we choose to call Strategic Flexibility, we looked at aspects such as technology leadership, knowledge management and organizational improvement activities within the $R \& D$ system.

The exact operationalization of $R \& D$ performance indicators differs from case to case and depends amongst others on the 'overall' performance requirements of the company involved (fourth column in Figure $2)$. In the case of Roessingh $R \& D$, we concentrated specifically on $R \& D$ quality performance. The ensuing groups of performance indicators can be found in the case description below.

\section{Methodology}

The steps that should be taken for this quality assessment are listed in Table 1. These steps are based on the Operations Strategy Framework outlined in the previous section, and tools based on the framework. In the next section we will present these tools, and illustrate and discuss the six steps and the tools, by describing their application to Roessingh R\&D.

\section{The case of Roessingh Research and Development}

\section{Step 1. Basic information and strategy}

The R\&D quality assessment starts with a descriptive collection of 'basic organizational information' (European Committee for Standardization, 1987). This includes listing the organization's legal status and structure, main products, number of employees; characterizing the market and competition; citing the company's goals and strategies; and describing in particular the R\&D staff (number, qualifications, experience) and how the

Table 2. Characteristics of Roessingh Research and Development B.V.

\begin{tabular}{ll}
\hline Legal form & Private company (B.V.); shares held by rehabilitation centre's executive \\
Business volume & 2.5 million Dfl \\
Employees & 20 full time equivalent \\
Scientific Research & - movement analysis \\
& - electro- stimulation \\
& - orthoses/prostheses \\
& - quality assurance \\
Diagnostic Services & EMG and force analysis \\
& - movement analysis \\
Products & - electromyografic simulators \\
& - bladder stimulators \\
- video-vector analysers & - subvention agencies, concern executive \\
Customers & - European research centres, hospitals and rehabilitation centres \\
& - University of Twente (NL) \\
Cooperation & - various European and American agencies \\
&
\end{tabular}


$\mathrm{R} \& \mathrm{D}$ department is imbedded in the organization. Furthermore, as it is important also to pay attention to the dynamics of the $R \& D$ function and its context, a brief history of how the company has adapted to environmental change is required here. It is very important that senior managers are involved in this step since consensus on the required performance characteristics forms the basis for the whole exercise.

Step 1 in practice: basic information on and strategy of Roessingh $R \& D$. For non-academic healthcare institutions it is quite uncommon to spend substantial amounts on research and development; it is even more unusual (at least in the Netherlands), to set up a research and development unit as a business function. 'Het Roessingh', one of the largest rehabilitation centres in the Netherlands, has founded its own private research and development department, Roessingh Research and Development (Roessingh R\&D). Initially the size of the centre and a large physician training programme attracted highly esteemed physicians with a positive attitude towards research. The absence of (large) research groups in the area of rehabilitation technology at the medical faculties of Dutch universities and the proximity of the University of Twente and its BioMedical Technological Institute reinforced this tendency and stimulated research activities. Confronted with ever-growing market influence in health care, the company considered that more investments in research and development were needed, based on a strate- gic approach towards R\&D. Consequently, in 1993, Roessingh R\&D's mission was formulated as the pursuit of a high standard and (inter)nationally acknowledged rehabilitation research in order to contribute to the scientific recognition of the rehabilitation centre. At present the main research activities are in the field of orthoses/prostheses, electro-mechanical control of body functions and development of neuro-psychological and locomotive movement analysis. Spin-off through service provision and product development is generated from this research in order to gain practical experience and feed back and furthermore to create a broad financial basis. In recent years Roessingh R\&D went through an expansion phase in which the field of activities broadened and the number of employees doubled to around twenty at present. Cooperation contracts with Dutch and German universities were made. In the research programmes, including cooperation with universities, about 60 researchers are active.

Essential processes for Roessingh $\mathrm{R} \& \mathrm{D}$ are knowledge/technology development (research projects) and knowledge/technology transfer in services that are either self exploited (such as gait analysis) or marketed as is the case with research projects leading to marketable products. Further details can be found in Table 2 .

\section{Step 2a. Quality Performance Profile}

The first requirement for effective control according to de Leeuw (1982) is to have an

Table 3. The R\&D Quality Performance Profile of Roessingh R\&D (Scientific Research activities).

\begin{tabular}{ll}
\hline Operational effectiveness & $\bullet$ direct contribution of Scientific Research to financial results \\
(External quality) & $\bullet$ number of proposed projects \\
& $\bullet$ number of sustained project proposals \\
& $\bullet$ number of project leaderships in European projects \\
& $\bullet$ number of contributions to seminars and conferences \\
& $\bullet$ overrun of subsidized budget in projects \\
Operational effectiveness & $\bullet$ throughput time of a project \\
(Internal quality) & $\bullet$ overrun of estimated hours for a project \\
& $\bullet$ overrun of use of (physical) resources \\
Strategic flexibility & $\bullet$ number of courses followed \\
& $\bullet$ co-operation with other institutes with respect to technology transfer \\
\hline
\end{tabular}


Petra C. de Weerd-Nederhof et al.

objective or set of objectives, or at least a mechanism to evaluate performance and performance improvement. This is the purpose a quality performance profile should serve. Following the competing values approach, company-specific, rather than generic, indicators should be drawn up together with e.g. the R\&D manager and/or his boss, who should also specify for each indicator the so-called IST and SOLL measure (current and preferred future measure).The latter is needed for step 6: to prioritize possible improvements and define goals for the improvement activities.

Step $2 a$ in practice: the Quality Performance Profile of Roessingh $R \& D$. Note that the underlying reason for this assessment at Roessingh R\&D was to guarantee a forefront position of the research programmes and development activities in the future (strategic flexibility) as well as to enable a smooth development of activities in closer cooperation with industry (operational effectiveness). The vision of the management was that through a systematic approach for quality assurance both these goals could be pursued. The assessment has therefore been undertaken from a quality viewpoint and first of all it was decided to use quality labels for the first level of $R \& D$ performance indicators. Operational effectiveness was divided into external and internal quality (EQ and IQ respectively), in line with a diagnosing instrument for product development processes from a quality viewpoint, also developed at the University of Twente (ten Broeke and de Weerd-Nederhof, 1995). Three different Quality Performance Profiles were drawn up: for Scientific Research, Diagnostic Services, and Products. The Quality Performance Profile for the scientific research activities of Roessingh $R \& D$ is presented in Table 3. It is remarkable that Roessingh R\&D (and also other companies to which this framework was applied) was reluctant to quantify IST and SOLL measures, which is the reason why they are not mentioned here. The IST-values were not always known, although they could be measured. Even then, management would prefer to indicate SOLL in terms of 'better', 'higher', or 'lower', rather than mention a 'hard' figure, considering also that such figures would differ between e.g. (types of) projects (e.g. throughput time), between

Table 4. The R\&D Function Profile: examples for Roessingh R\&D.

\begin{tabular}{lll}
\hline R\&D performance level & Applicable to area of & R\&D function characteristics \\
\hline $\begin{array}{l}\text { Operational effectiveness } \\
\text { (External quality) }\end{array}$ & R\&D Process & $\begin{array}{l}\text { The research design is assessed and approved in order to } \\
\text { guarantee it will meet specified requirements. }\end{array}$ \\
& R\&D Management & $\begin{array}{l}\text { A clear project-management function leads the project } \\
\text { throughout all phases. } \\
\text { Continuous scanning of the environment and good feed } \\
\text { back provide input for the R\&D process. }\end{array}$ \\
$\begin{array}{ll}\text { Operational effectiveness } \\
\text { (Internal quality) }\end{array}$ & R\&D Process & $\begin{array}{l}\text { All employees act according to the concept of external and } \\
\text { internal customers. }\end{array}$ \\
& R\&D Management & $\begin{array}{l}\text { There is optimal alignment of policy development by } \\
\text { various professional disciplines. }\end{array}$ \\
& R\&D Context & $\begin{array}{l}\text { Important external parties such as potential partners and } \\
\text { customers/users are involved in the process. }\end{array}$ \\
Rtrategic flexibility & R\&D Process & $\begin{array}{l}\text { Employees can be characterized as: creative, innovative } \\
\text { and self-reliant in their activities. }\end{array}$ \\
& R\&D Management & $\begin{array}{l}\text { Standard project evaluation and result-indicators are used } \\
\text { for feed back in order to improve various process elements. } \\
\text { Fit with the extra-organizational context is continuously } \\
\text { ensured based on frequent SWOT-analysis and } \\
\text { benchmarking. }\end{array}$ \\
\hline
\end{tabular}


employees (e.g. number of courses followed), and so on.

\section{Step 2b. R\&D Function Profile}

The R\&D Function Profile characterizes the R\&D function and its context. Again, this profile, should be drawn up in cooperation with management. Using the results of steps 3 and 4, this profile is completed in step 5 and used to assess and analyse R\&D quality, by giving a score for the most important R\&D function characteristics per type of quality. Entries in the R\&D Function Profile can be found using, for example, quality standards like ISO 9000, BS 7000, and the European, the Baldridge, and/or countryspecific Quality Awards (European Committee for Standardization, 1987; British Standards Institution, 1989; Hardjono and Hes, 1993). As these standards are rather generic, they needed to be 'restructured'and operationalized for this particular case. Furthermore, the standards focus mainly on product development and design, so when considering more fundamental $R \& D$ processes, some of the characteristics have to be reformulated. It should also be mentioned that the overall $R \& D$ function profile is a summary of the profiles (so-called checklists) for each element of the R\&D system (people, resources/systems and tools, R\&D process, organizational arrangements, control and support processes, interactions with intra- and extra-organizational context; see also Figure 3), which are a part diagnosing instrument (ten Broeke and de WeerdNederhof, 1995) referred to above.

Step $2 b$ in practice: $R \& D$ Function Profile for Roessingh $R \& D$. R\&D function characteristics related to Operational Effectiveness and Strategic Flexibility were derived from the quality standards mentioned above and reformulated to fit the character of the more fundamental research, the terminology and the particular characteristics of Roessingh $\mathrm{R} \& \mathrm{D}$, and then used to analyse the organization. Three R\&D Function Profiles were drawn up, based on different quality standards, to distinguish between Scientific Research, Diagnostic Services and Products. Whereas the Quality Performance Profiles did differ to a considerable degree, these
R\&D function profiles only differed on specific details, such as the reference to the protocols used in Diagnostic Services. In Table 4, one example is mentioned relating each type of quality to the $R \& D$ process, its management and context.

\section{Step 3. $R \& D$ elements and their attributes}

In terms of the Operations Strategy Framework, the elements of the R\&D system that have to be described for the quality assessment are the $R \& D$ primary process; the strategic, adaptive and operational management and support processes; process inputs and outputs; people and resources; and organizational arrangements (see Figure 3). For all people involved, attributes are described such as: age and tenure; function, tasks, responsibilities and authorities; education and experience; motivation; power and political behaviour. For project leaders, style of leadership is added, and for project team members their role in the team. For teams (an organizational arrangement), age and duration; size; structure and composition; autonomy; and culture are described. For all these system-technical and socialdynamic attributes, both the formal and the informal, the official and the factual situation as well as differences between, and recent changes in, these situations are recorded. Finally, their influence on the functioning of the $R \& D$ function is assessed.

Step 3 in practice: $R \& D$ elements and attributes at Roessingh $R \& D$. The R\&D elements and attributes at Roessingh $R \& D$ were described using the descriptive tables and schemes of the previously mentioned diagnostic instrument (see Brown and Eisenhardt, 1995), which was designed for product development from a quality viewpoint. This led to a less detailed picture than suggested in Figure 3, but at more than 20 pages, it was a comprehensive and sufficiently accurate description. The advantage of this practical approach was that by using these preshaped tables and schemes, through the concepts of EQ, IQ and SF, a direct link was possible with the Quality Performance Profile and the R\&D Function Profile. These profiles in their turn were closely linked to the ISO and BS 
standards management which Roessingh wanted to use as a basis for their quality policy. Below a short characterization of the R\&D system and its context at Roessingh $\mathrm{R} \& \mathrm{D}$ is given.

R\&D projects are initiated by concrete proposals from the Products or Diagnostic Services groups, combined with ideas that have a high chance of getting subsidies. For each project a schedule is drawn up, and a project leader is assigned, but there are no formal procedures for, for example, division of labour, evaluation and milestones. Therefore it depends on, for example, the demands of the funding body whether these aspects are worked out in detail in the project plan, or not. The R\&D workers are specialists, academics who work almost autonomously in a project; they are result-oriented and highly motivated as they feel their work is really beneficial to society. For co-ordination informal structures are emphasized. Knowledge and ideas are mostly exchanged towards the end of a project, which is often too late to integrate ideas of colleagues. Projects are not evaluated systematically. Project leaders and cluster managers are formally responsible for operational project management, but actually this is delegated to the R\&D people themselves. The organization has grown rapidly, but the organizational arrangements have not yet been adapted to its current size: the organization is working to improve this situation (adaptive management). At the strategic level, management is mostly concerned with getting the financial and human resources to be able to maintain 'market leadership' in rehabilitation technology research. Emphasis is placed on achieving the right balance between short (less than 1 year) and long term (up to 3-4 years) projects. The latter is important to be able to give people longer term contracts.

\section{Step 4. Context}

The context of R\&D functions is defined as all elements outside the boundary of the $R \& D$ system that may affect all or part of the $\mathrm{R} \& \mathrm{D}$ system. The intra-organizational context comprises the other business functions (Figure 3). Important extra-organizational elements are the suppliers of goods, services and technologies (people and resources). Customers affect both the input (customer demands as perceived by the R\&D function, either directly or indirectly, through the marketing function) and the output (customers actually buying products/ services). Other sectors, such as the financial, socio-cultural, economic and government sectors, may exercise quite some influence as well.

It is not necessary to describe every element in the intra- and extra-organizational context in detail. Following an inside-out approach (R\&D system first, context next) it is possible to identify the relevant contextual elements through the examination of inputoutput relationships of the $R \& D$ processes (primary, management and support). For each contextual element the following key questions are asked:

- What kind of alignment is necessary?

- How does alignment take place?

- Is the alignment satisfactory?

- Are there any bottlenecks?

- Have there been any contextual changes recently; if so, what have been their effects?

Step 4 in practice: the context of the $R \& D$ functions of Roessingh $R \& D$. For the description of the interactions with the intraand extra-organizational context at Roessingh $R \& D$ again preshaped tables from the diagnostic instrument were used. From a quality viewpoint this gave sufficient information, which is summarized (mainly for the Scientific Research Group) below.

Since Roessingh R\&D mainly consists of one primary function, $R \& D$, intra-organizational alignment is not really applicable here, except in terms of exchanging experiences and knowledge between the Scientific Research Group and the other two groups (Diagnostic Services and Products). However, alignment with the extra-organizational context is very important. Most projects of the Scientific Research group at Roessingh R\&D are externally funded. Consequently, funding bodies have great influence on the specifications of projects. Relationships with the academic world are very good, through participation in projects and conferences, and joint publications. Alignment with other extra-organizational elements, such as pati- 
ents and doctors on the one hand, and manufacturers of products on the other, is not yet optimal. Most projects have a 'technology push' character, and do not take the wishes and expectations of these important parties into account at an early enough stage. Patients are also important for testing the equipment; in order to do this it is necessary by law to obtain approval from the 'Medical Ethics Committee' and to use informed consent documents. Sometimes insurance companies are also an important extra-organizational party.

\section{Step 5. Quality assessment}

From the description of the R\&D elements and their attributes on the one hand and both the intra- and extra-organizational R\&D context on the other, R\&D quality can be assessed in terms of EQ, IQ and SF by filling in the R\&D Function Profile as defined in step $2 b$ above. Of course it is not always possible to quantify the 'degree' of EQ, IQ or SF but it appears that well explained + (good), + I- (sufficient) and - (insufficient) marks indicate whether the design of the $\mathrm{R} \& \mathrm{D}$ function is satisfactory or not.

Step 5 in practice: quality assessment in Roessingh $R \& D$. Before going into the scores in terms of EQ, IQ and SF for Roessingh $R \& D$, it must be mentioned that especially the R\&D Function Profile was drawn up with the future in mind: Roessingh R\&D intends and is expected to work together more with external parties, which requires better performance in terms of for example quality of documentation, structured and systematic ways of working and 'organizational' learning.

As to external quality Roessingh R\&D scored very well in terms of budget discipline, sticking to time schedules and complying with health care demands and regulations. This is reflected by clinical leadership of various European research projects, the recent recognition by various national agencies of leadership in rehabilitation technology and leading positions of different staff members in international organizations (e.g. research groups). Systematic scanning of market needs and analysis of potential customer needs and feed back of project results from external stakeholders could however be improved.

Internal quality: although Roessingh $\mathrm{R} \& \mathrm{D}$ scored reasonably well in terms of the Quality Performance Profile, this was not achieved through the characteristics of the R\&D system that were expected to be important in terms of the R\&D Function profile. For example, due to the limited size of Roessingh R\&D, informal contacts between staff members are at present an essential coordination tool. Formal presentations of results and experiences take place only at the end of projects, so there is no organized moment of interim verification that all possible knowledge is employed for a specific research task. No formal or consistent informal procedures for project management (division of labour, evaluation, etc.) were found.

Strategic flexibility: essentially the same remarks apply as under IQ. At the moment Quality Performance looks OK, but this is not a very stable, well documented situation, as appears from the R\&D Function Profile. As an example: no systematic internal project evaluation is done, so staff members receive little feedback on the results of their work. In this way there is no systematic transfer of useful experiences for learning across projects that are carried out at the same time or even, longitudinally, between subsequent projects. Management activity is mostly focused on bringing in sufficient resources to be able to comply to the mission, meaning that less time is devoted to adaptive management or support activities in terms of knowledge management.

\section{Step 6. Diagnosis and managerial implications}

In step 6 , the quality assessment has to be related to the SOLL measures that were defined by management in the Quality Performance Profile in step 2a, in order to be able to formulate and prioritize improvement plans. This preferred state as defined by management might however be somewhat subjective, and is usually described in very qualitative terms and on a highly conceptual level. It would therefore be helpful if a more objective, concrete and operationalized model were available for comparison. Qual- 
ity standards and benchmarks such as Adler et al.'s description of technical functions (Adler, McDonald and MacDonald, 1992) can to some extent be used for this purpose. In our opinion however, it is one thing to use these standards for the purpose of quality assessment, but to consider them ideal models is something else. These standards or norms were defined for the purpose of certification but, considered applicable in every situation, they do not take the specific characteristics of an individual company into account.

Step 6 in practice: implications for Roessingh $R \& D$. Three major areas of improvement were distinguished for Roessingh $\mathrm{R} \& \mathrm{D}$ : market-orientation (EQ), formal procedures for internal alignment (IQ) and stimulation of organizational (in addition to 'just' individual) learning (SF). As was the intention from the beginning, the company decided to formulate an integral quality policy to deal with these weak spots. This quality policy should eventually lead to Total Quality Management. Combined with certification at a later date, this is of paramount importance for Roessingh $\mathrm{R} \& \mathrm{D}$ if they would want to continue carrying out more work for other institutes than the Rehabilitation Centre alone. This quality policy would primarily be based on BS 7000 . Although this standard focuses mainly on product development and design, it was considered a good basis for the quality policy, mainly because of the explicit distinction in this standard between senior/top management, project leaders and individual scientists/engineers. Of course since more fundamental $R \& D$ processes are involved, some of the characteristics of the standard have to be reformulated. During the quality assessment the $\mathrm{R} \& \mathrm{D}$ people had already made clear that they would not be happy with more formal procedures. To some extent this was surprising since there is already an extensive set of regulations and procedures for the use of the laboratory, and these did not invoke much resistance. Still, this was an important point to be taken into account when designing and implementing the policy.

The new quality policy is characterized by Roessingh R\&D's management as a dynamic (global) approach, taking the specific profes- sional coordination mechanisms into account, creating a learning environment and generating management influence on input, process and output in a market oriented setting. There were two main activities to be discerned: knowledge production in research, sometimes leading to marketable products, and knowledge transfer in services. Quality assurance activities should be applicable to both, if possible; or differ as little as characteristics of both processes allow.

For the first activity (Scientific Research, sometimes combined with Products) a dynamic, conceptual implementation of the BS 7000 norms for managing product design is preferred as it takes into account both the different management levels, their possible impact on the actual knowledge-generating projects and the typical project management aspects. Each project leader should not just be market-oriented but actually be pro-active to scan for new possibilities and developments in the (subvention) market. Being market-oriented in this kind of organization has many sides: doctors and patients; financers and insurance companies etc. The research programme thus has to be based on four aspects: requirements of the subvention agency; demands of the potential customer or user of the project results; scientific demands; and organizational requirements.

Project management responsibilities and authorization will be organized according to BS 7000 norms. After every project an evaluation has to be carried out, either by organized sessions or structured evaluation forms. For Diagnostic Services a dynamic, conceptual application of the ISO-9004.2 norm is recommended. Principally the schedule of: market orientation, service design, process delivery and evaluation of results in a feed back cycle, is the basic lay-out of the ISO-approach. Market analysis in health care concerns three main types of customers: professional users (mainly referring medical specialists), paying agencies (health insurances, third-party insurance, legal agencies) patients/clients. Service design is the process of weighing the requirements of different customers and stakeholders against professional views and experience in order to develop a professional service that meets external and internal requirements as much as possible. Process control and efficiency 
can be achieved by mechanisms as described under project management; usually, however, a certain level of standardisation according to written protocols is possible. The last phase is evaluation of results either on individual cases or on an aggregate base in order to generate feed back information for control and further improvement.

\section{Implementation}

In order to implement the policy mentioned above, the personnel will have to be trained on both the principles of quality assurance and certain aspects of project management. Furthermore, certification according to the ISO or BS standard needs to be pursued in order to be able to realize a larger budget share in contract-research. Based on the diagnostic instrument a set of quality performance indicators could be defined to guide the process. These range from 'number of publications' and 'number of sustained project proposals' to project characteristics and strategic indicators such as the number of effective cooperation contracts with other (European) institutions.

As said before, a special point of attention during the implementation phase will be the natural aversion of professionals towards strict organizational regulations versus the need to implement some form of regulated quality assurance. The R\&D workers' perception of quality standards is that they imply bureaucracy ('a lot of unnecessary paperwork to start with'). Experience elsewhere (van Harten, 1995) has shown that it is possible to start with a conceptual approach and to proceed to rules and regulations, as needed in some forms of certification, in a later stage. This is probably the best approach to overcome the current resistance against 'bureaucratic' standards. When a learning approach is chosen there is maximum guarantee that the chosen form of quality assurance will grow along with the unit.

\section{Conclusions and further research}

The approach to assessing $R \& D$ quality performance presented and illustrated in this paper, seems to be a useful instrument to

(C) Blackwell Publishers Ltd 1997 help managers to identify, analyse, understand and communicate the strengths and weaknesses of the R\&D function, as regards its performance in terms of both Operational Effectiveness (internal and external quality) as well as Strategic Flexibility. A particularly interesting feature of the approach is its flexibility. Not only can it be used to assess R\&D performance in its broadest sense (as we described de Weerd-Nederhof et al., 1994; de Weerd-Nederhof et al., 1996; de Weerd-Nederhof and Boer, 1996; ten Broeke and de Weerd-Nederhof, 1995) but also to focus on one aspect, for example R\&D quality, as in the present paper. As a quality manager of one of the case companies stated: the advantage of the approach over ISO-like audits is that Strategic Flexibility is considered explicitly and that more attention is paid to the people working in the $R \& D$ process and their notion of and contribution to quality.

However, the strengths of the approach are also the most difficult features to apply in practice. Strategic flexibility and socialdynamic attributes are still problematic in terms of operationalisation and data collection. This makes the approach very dependent on the extent to which the people who carry out the assessment understand the underlying principles of the tools and framework, meaning that the approach cannot as yet be used for self-assessment by management without the help of the researchers who developed the tool. Also, there are still difficulties in objectively and comprehensively measuring R\&D performance. This is not only true for our framework, but it is a common problem featuring frequently in recent $R \& D$ literature. Furthermore there is a lack of situation-specific reference models that can be used for prioritizing improvement activities after assessing R\&D quality, useful as quality standards may be, in this respect.

The research reported in this paper is part of a larger project which aims to find (clusters of) effective $R \& D$ configurations with matching performance profiles, that can partially serve as exemplary models. In order to achieve this, a number of case studies will have been carried out using an extended version of the framework described in this paper. As this project does not only take quality but also cost and timeliness into 
consideration, it will be possible to use the resulting exemplary models as a reference for the purpose of diagnosis. Performance measurement issues are addressed in a closely related research project (Kerssens-van Drongelen, 1995), the results of which will be integrated in an update of the step-by-step approach. Although we do not expect to be able to overcome all difficulties in assessing strategic flexibility and describing socialdynamic aspects, we hope to gain enough experience from the case studies and to be able to make a big step forward in this respect. It is very encouraging that the application of the framework and mapping tools in their current form was already very valuable to Roessingh $\mathrm{R} \& \mathrm{D}$, as the collective responsibility for this paper, rightly, suggests.

\section{Acknowledgements}

The tools described in this paper are based on joint research in which also Jose Gieskes, Andre ten Broeke, Bart Bossink, Hans Bastiaans and Olaf Fisscher were involved. The analysis of Roessingh R\&D was carried out by Henk Jan Wegman.

\section{References}

Adler, P.S., McDonald, D.W. and MacDonald, F. (1992) Strategic management of technical functions. Sloan Management Review, Winter.

Boer, H. and Krabbendam, J.J. (1991) Organizing for marketoriented manufacture, POMS Conference, New York City, USA, November $11-13$.

Bossink, B.A.G., Gieskes, J.F.B. and Pas, T. (1992) Diagnosing total quality management-part 1. Total Quality Management, 3, 3, $223-231$.

British Standards Institution (1989) Guide to managing product design, BS7000, London, UK.

Broeke, A.M. ten and Weerd-Nederhof, P.C. de (1995) Beoordeling van produktontwikkelingsprocessen, Organisatie Instrumenten File A1030, Samsom Bedrijfsinformatie BV, Alphen aan de Rijn, December 1995 (in Dutch).

Brown, S.L. and Eisenhardt, K.M. (1995) Product development: past research, present findings and future directions, Academy of Management Review, 20, 2, 343-378.

Draaijer, D.J. and Boer, H. (1995) Designing market-oriented production systems: theory and practice. Integrated Manufacturing Systems, 6, 4, 4-15

European Committee for Standardization (1987) Ouality systems Model for quality assurance in design/development, production, installation and servicing, EN 29001/NEN-ISO 9001, Dutch version, December.

Hardjono, T.W. and Hes, F.W. (1993) De Nederlandse kwaliteitsprijs en-onderscheiding. Deventer, The Netherlands. Kluwer Kwaliteitskunde (in Dutch).

Harten, W.H. van (1995) Kwaliteitszorg, systematische aanpak door/in revalidatiecentrum "Het Roessingh". Handboek Kwaliteit van Zorg, VUGA (in Dutch).

Hayes, R.H. and Wheelwright, S.C. (1995) Restoring Our Competitive Edge. New York, John Wiley \& Sons.

Hedge, D.G. (1989) Quality in R\&D culture and practice. 2nd International Total Ouality Management Conference. London.

Hill, T. (1995) Manufacturing Strategy. Basingstoke, Macmillan.

Kerssens-van Drongelen, I.C. (1995) Performance measurement in R\&D processes, Research proposal, School of Management Studies, University of Twente, Enschede, The Netherlands, December.

Leeuw, A.C.J. de (1992) Organisaties: management, analyse, ontwerp en verandering, een systeem visie. Assen, The Netherlands: Van Gorcum.

Murray, T.J. (1987) Quality in R\&D: meeting the new quality challenge. Research Management, 11, 25-31.

Paashuis, V.J.B.J. and Boer, H. (1995) New product design: organising for integration. 2nd International EurOMA Conference on Management and New Production Systems. University of Twente, Enschede, The Netherlands, 28-31 May.

Skinner, W. (1985) Manufacturing, the Formidable Competitive Weapon, New York, John Wiley \& Sons.

Weerd-Nederhof, P.C. de and Boer, H. (1996) Description of R\&D systems, context and performance. Assessing operational effectiveness and strategic flexibility. 3rd International Product Development Conference, Fontainebleau, France, April 15-16,

Weerd-Nederhof, P.C. de, Boer, H., Fisscher, O.A.M. and Gieskes, J.F.B. (1996) Assessing R\&D quality. Towards a descriptive model of R\&D systems, context and quality performance. 1996 $R \& D$ Management Conference on Quality and $R \& D$, Enschede, The Netherlands, March 6-8.

Weerd-Nederhof, P.C de, Gieskes, J.F.B and ten Broeke, A.M. (1994) Organizing for quality in product development. Towards a practical instrument for diagnosing product development processes from a quality point of view. 2nd EIASM Product Development Conference, Gothenburg, Sweden, May 30-31. 